\title{
DEVELOPMENT OF TITANIUM NITRIDE COATING FOR SNS RING VACUUM CHAMBERS*
}

\author{
P. He, H.C. Hseuh, M. Mapes, R. Todd ${ }^{\dagger}$ and D. Weiss \\ Collider-Accelerator Department, BNL, Upton, NY 11973, USA
}

\begin{abstract}
The inner surface of the ring vacuum chambers of the US Spallation Neutron Source (SNS) will be coated with $\sim 100 \mathrm{~nm}$ of Titanium Nitride (TiN). This is to minimize the secondary electron yield (SEY) from the chamber wall, and thus avoid the so-called e-p instability caused by electron multipacting as observed in a few high-intensity proton storage rings. Both DC sputtering and DCmagnetron sputtering were conducted in a test chamber of relevant geometry to SNS ring vacuum chambers. Auger Electron Spectroscopy (AES) and Rutherford Back Scattering (RBS) were used to analyze the coatings for thickness, stoichiometry and impurity. Excellent results were obtained with magnetron sputtering. The development of the parameters for the coating process and the surface analysis results are presented.
\end{abstract}

\section{INTRODUCTION}

Brookhaven is undertaking the design, construction and commissioning of the SNS accumulator ring. The operating pressure of the ring vacuum system [1] will be $10^{-9}$ Torr and is needed to minimize the beam-residual gas ionization. At the designed vacuum level, the rate of ionization and electron production is approximately $10^{-3}$ electrons per proton over the one-millisecond accumulation cycle. These primary electrons, heated by the oscillating beam-wall potential generated by the passing bunches, liberate more electrons when bombarding the vacuum chamber wall. The electron multipacting and resulting e-p instability can limit the achievable proton intensity when excessive electrons are generated and trapped. One major contributing factor to e$\mathrm{p}$ instability is the SEY of the vacuum chamber wall. Most SNS ring chambers are made of stainless steel, which has a peak SEY of $\sim 2.5$ and can be reduced to $~$ 1.5 if the surface is coated with TiN. TiN coating has been routinely applied to high power RF windows and tuners to reduce multipacting. TiN coating of regular accelerator beam tubes was done for the $2 \mathrm{~km}$ PEPII LER using DC sputtering [2]. Due to the much larger cross sections of the SNS chambers, development of a suitable coating process and associated parameters is necessary to ensure the quality of the coating.

\section{TiN COATING DEVELOPMENT}

The SNS ring has a circumference of $248 \mathrm{~m}$. It consists of 4 arc sections of $34 \mathrm{~m}$ each and 4 straight sections of $28 \mathrm{~m}$ each. There are 32 half cell chambers of four types varying slightly from one to the others.

\footnotetext{
*Work performed under the auspices of the U.S. Department of Energy
} 'rtodd@bnl.gov

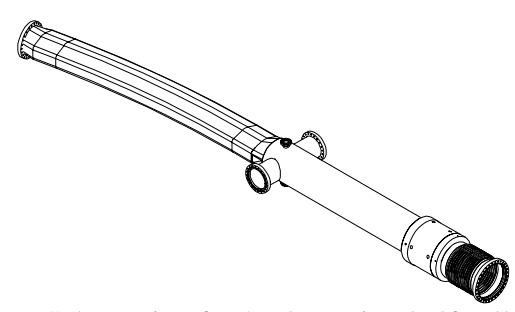

Figure 1. Schematic of a $4 \mathrm{~m}$ long ring half cell chamber.

Development of the coating process for the half cell chambers was done in a 8" diameter test chamber, as shown schematically in Figure 2, that closely matched the cross section and length of the half-cell chamber.

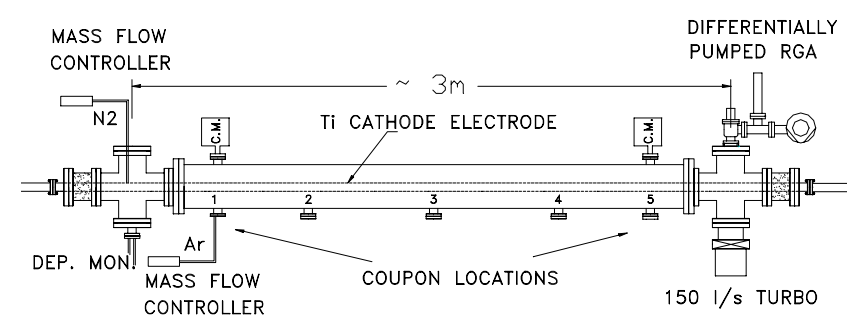

Figure 2. Setup of TiN coating development of half cell chambers using either DC or magnetron sputtering.

The length of the test chamber is greater than half the length of the half cell chamber to ensure that there are no scale-up problems. Stainless steel coupons located through the ports along the bottom were later analyzed for the quality and longitudinal uniformity of the film. Both straight DC sputtering and DC magnetron sputtering were tested. Early testing showed a deposition rate for magnetron sputtering $\sim 10$ times of that of DC sputtering with much lower operating voltage and pressure. This is a result of the increased ion density formed by the electrons confined within the magnetic field, which adds to the sputtering rate. Additionally, improved stoichiometry and uniformity were achieved with magnetron sputtering. Consequently, DC sputtering was abandoned and magnetron sputtering was further developed.

Much work has been done on the formation of TiN by magnetron sputtering as an industrial hard coating using planar electrodes and magnets. However, due to our chamber geometry, a novel approach had to be taken in developing a cathode target with suitable magnetic field characteristics. Commercially available Alnico magnets $1 \frac{1}{4}$ " diameter and 2 " in length were inserted in a $1 \frac{1 / 2}{2}$ 
diameter, grade- 2 titanium tube. A $1 / 2$ " hole in the center of the magnets allowed for water cooling of the cathode. The deflection of the long cathode was found to be within acceptable limits. Furthermore, this small cathode could conform to the curvature of the dipole section of the half cell chambers. The magnets were stacked with opposing poles using non-ferrous $1 / 2$ " spacers resulted in a looping magnetic field of sufficient strength to project from the cathode surface. This "low cost" cathode worked in conjunction with a $10 \mathrm{KW}$ DC power supply to produce the satisfactory field and discharge plasma as shown in Figure 3.

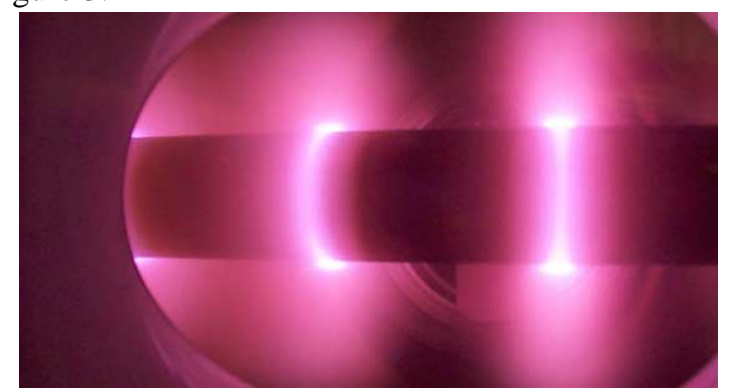

Figure 3. Discharge characteristics of DC magnetron sputtering, with bright rings at the locations of non-magnetic spacers.

It was necessary to determine if the coating would have acceptable thickness uniformity along the length. Treating each plasma ring as a point source, a thickness distribution on a flat surface (i.e. chamber wall) located $8.3 \mathrm{~cm}$ away was calculated using a point source cosine distribution [3]. Based on a plasma ring spacing of $6.6 \mathrm{~cm}$, the superposition of the individual thickness distributions resulted in an overall uniformity within $\pm 10 \%$ (Figure 4).

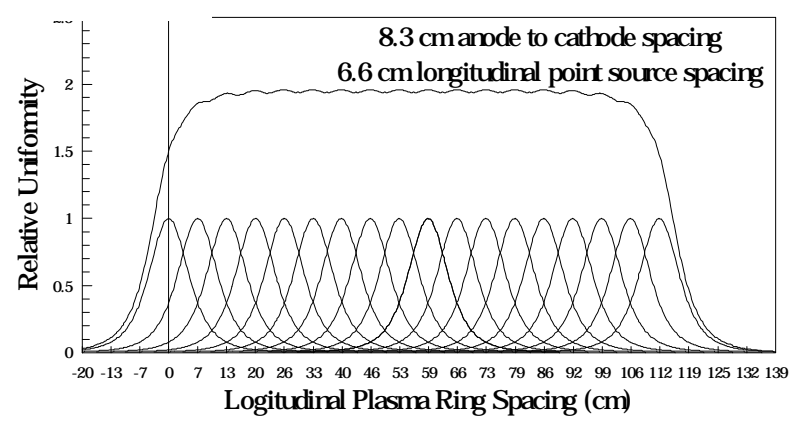

Figure 4. Longitudinal film uniformity based on point source cosine distribution

The reactive process was controlled using partial pressure feedback of nitrogen gas [4]. Mass flow controllers were used to introduce both argon and nitrogen, while a differentially pumped quadrupole residual gas analyzer was used to monitor nitrogen partial pressure. The nitrogen was introduced through a $1 / 4$ " diameter Ti tube which runs the length of the cathode. Small (i.e. 10 $10^{-2}$ inch dia.) holes located every six inches provided even distribution of reactive gas, which was necessary for consistent color and composition throughout the length of the chamber. All testing was done with the chamber at a temperature of $250^{\circ} \mathrm{C}$.
The TiN reactive process is well understood and has been described previously [5]. A hysteresis curve of nitrogen consumption was generated (figure 5).

Figure 5. Nitrogen hysteresis with constant Ar flow showing the effects of target nitriding on nitrogen consumption.

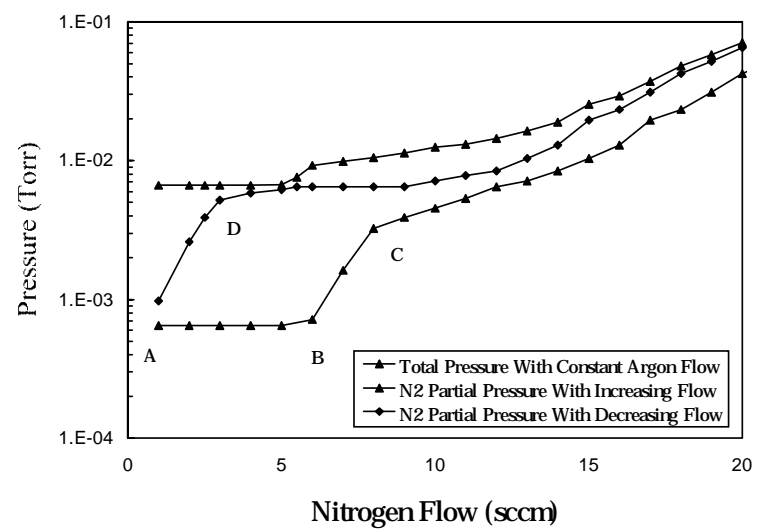

It has been reported that a deposition rate for $\mathrm{TiN}$ approaching that of pure $\mathrm{Ti}$ can be achieved when operating in the region $A B$. Increasing the $\mathrm{N}_{2}$ flow rate

\begin{tabular}{c|c|c|c|c|c|c|c|c|c}
$\begin{array}{c}\text { Sputtering } \\
\text { Mode }\end{array}$ & $\begin{array}{c}\text { Operating } \\
\text { Region }\end{array}$ & $\begin{array}{c}\text { Ar Flow } \\
\text { (sccm) }\end{array}$ & $\begin{array}{c}\text { N2 Flow } \\
\text { (sccm) }\end{array}$ & $\begin{array}{c}\text { Ptotal } \\
\text { Torr }\end{array}$ & Volts & Amps & & $\begin{array}{c}\text { Dep. Rate } \\
\text { Aithr N(x) }\end{array}$ & $\begin{array}{c}\text { O \% } \\
\text { by AES } \\
\text { by AES }\end{array}$ \\
\hline \hline straight DO & $\mathrm{B}$ & 8.3 & 0.9 & $3 \mathrm{e}-2$ & 4500 & 0.06 & 200 & 1.16 & 7.1 \\
\hline magnetron & $\mathrm{B}$ & 13.7 & 11 & $6 \mathrm{e}-3$ & 308 & 10 & 2000 & - & - \\
magnetron & $\mathrm{C}-\mathrm{D}$ & 13.3 & 7 & $8 \mathrm{e}-3$ & 300 & 4.5 & 1000 & 1.2 & - \\
magnetron & $\mathrm{D}$ & 13.3 & 2.75 & $6 \mathrm{e}-3$ & 300 & 4.5 & 1000 & 1.22 & 3
\end{tabular}

further results in a sharp decrease in deposition rate as the target is poisoned or nitrided (i.e. formation of TiN on the cathode surface). Additionally, the stoichiometry, and hence the color of the film is largely based on the $\mathrm{N}_{2}$ flow rate. As the $\mathrm{N}_{2}$ flow rate approaches point $\mathrm{C}$, the film becomes over stoichiometric resulting in a brownish color. Poor longitudinal color (i.e. gold to silver or TiN to pure $\mathrm{Ti}$ ) and poor thickness distribution were observed when operating in the region $\mathrm{AB}$. It was found that the best results were obtained by first nitriding the cathode by increasing $\mathrm{N}_{2}$ flow above point $\mathrm{B}$ and then lowering to just above point $\mathrm{D}$. By operating in this condition, a stable plasma was formed, resulting in a uniform longitudinal color. The results are summarized in the following table:

Note: Coatings by magnetron sputtering exhibited significantly lower oxygen content partly due to the high plasma density, resulting in an increased presence of atomic nitrogen competing over oxygen for available sites.

\section{ANALYSIS OF COATING PROPERTY}

Stainless steel witness coupons were mounted in the bottom ports along the test chamber (Figure 2). Film stoichiometry and thickness of the coupons were analyzed by AES and RBS, respectively. The Secondary Electron Yield (SEY) of coated coupons was measured at CERN.

\subsection{Auger Electron Spectroscopy (AES)}

AES analysis was conducted on the coupons using a modified PHI4300 Scanning Auger Microprobe (SAM) with incident electron beam of $10 \mathrm{keV}$ and $10 \mathrm{nA}$. Survey scans for all elements ( $\mathrm{Li}$ to $\mathrm{U}$ ) were acquired on the as- 
received surfaces. Depth profiles were obtained by alternating an acquisition cycle with a sputtering cycle. The sputtering cycles remove material from sample surface using a $4 \mathrm{keV} \mathrm{Ar}^{+}$source rastered over a $3 \mathrm{~mm} \times 3 \mathrm{~mm}$ area. To eliminate crater-wall effect, the data were acquired from a smaller region in the center of the sputtered area. Typical results of AES analysis are shown in Figure 6.

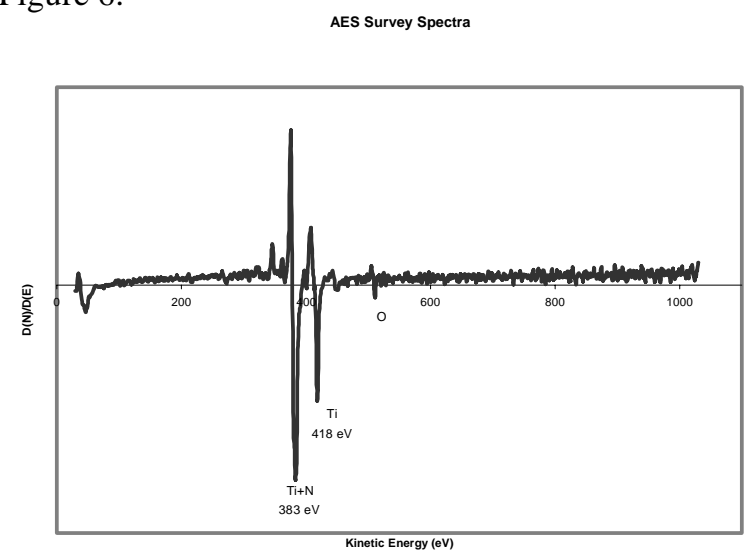

Figure 6. AES analysis of sputter cleaned TiN sample, showing little oxygen or carbon contamination in the coated film and correct stoichiometric ratio of $\mathrm{Ti}$ to $\mathrm{N}$.

\subsection{Rutherford Backscattering (RBS)}

RBS uses a $2-\mathrm{MeV} \mathrm{He}^{++}$ion beam as the probe. The analyzer detects backscattered ions at $120^{\circ}$ and $160^{\circ}$ from both aligned and nonaligned directions with typical accumulated charge of $50 \mu \mathrm{C}$. The RBS spectra shown in Figure 7 provide precise information on coating thickness and composition. The Ti to $\mathrm{N}$ ratios were consistently in the 0.9-1.1 range with coating thickness of $\sim 400 \mathrm{~nm}$ after 3 hours of coating. The profile indicated that the energetic nitrogen and titanium penetrated the iron substrate and formed intermediate layers with thickness ranging from $20 \mathrm{~nm}$ to $50 \mathrm{~nm}$.

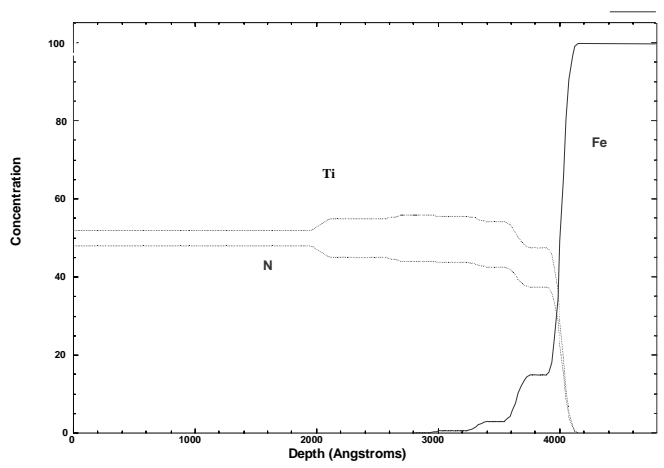

Figure 7. RBS depth profiles of TiN coated coupon give quantitatively the distributions of nitrogen, titanium in the coatings

\subsection{Secondary Electron Yield (SEY)}

TiN-coated coupons were sent to colleagues at CERN for SEY measurements. Electron beam with energy between 60 and $3000 \mathrm{eV}$ bombards the surface at normal incidence angle. All secondary electrons are collected to derive the SEY [6]. The measurements were done as received, without in-situ bake and with very low current and accumulative dosage (down to $\mathrm{nC} / \mathrm{mm}^{2}$ ) to minimize surface modification effects, since SEY is strongly dependent on the dose of primary electrons [6]. The difference in SEY between uncoated and TiN coated samples is illustrated in Figure 8. Compared to the bare stainlees steel, TiN layer has a significantly lower SEY.

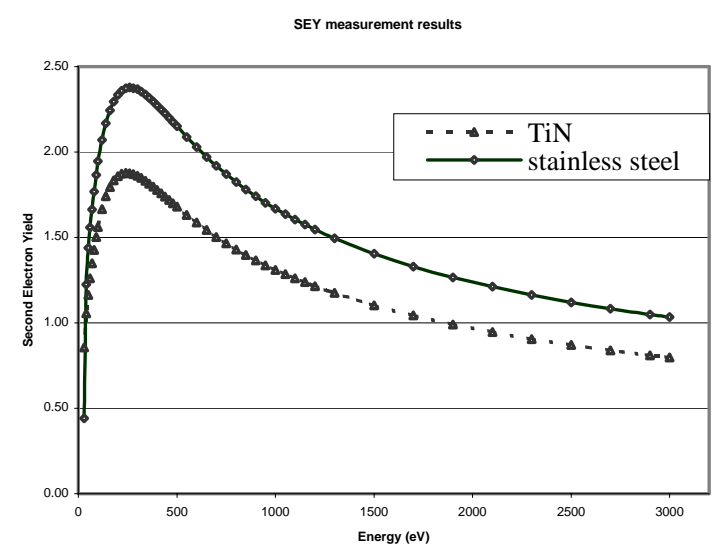

Figure 8. SEY as a function of incidence electron energy for bare and TiN coated stainless steel. The coating reduces the SEY by about $30 \%$.

\section{SUMMARY}

DC magnetron sputtering has been developed to coat the SNS ring vacuum chambers with TiN. The coating has correct stoichiometry, good adhesion and low SEY. The difficulties in producing a film with uniform properties within the long half cell chamber have been overcome with the development of a unique magnetron target. A production facility is being assembled to coat the large quantity of SNS production chambers.

\section{ACKNOWLEDGEMENT}

The authors would like to thank N. Hilleret and his colleagues at CERN LHC Vacuum Group for carrying out SEY measurements of TiN coated coupons, R. Sabatini of BNL for AES analysis of some coated samples, and C-A Vacuum Group in setting up the experiment.

\section{REFERENCES}

[1] H.C. Hseuh, C.J. Liaw and M. Mapes, Proc. 1999 Particle Accel. Conf., New York, pp1345-7 (2000).

[2] K. Kennedy, et al., Proc. 1997 Particle Accel. Conf., Vancouver, B.C., 3568 (1998).

[3] J.C. Helmer and C.E. Wickersham, J. Vac. Sci. Technol. A4, 408 (1986).

[4] W.D. Sproul, P.J. Rudnik and M.E. Graham, Surface and Coating Technol., 39/40, 355 (1989).

[5] L. Combadiere and J. Machet, Surface and Coatings Technol., 82, pp145-7 (1996).

[6] V.Baglin, et al., Proc. $7^{\text {th }}$ European Particle Accel. Conf., Vienna, Austria, pp217-221 (2000), CERN LHC Project Report No. 433, Sept., 2000. 